\title{
Acute Dystonic Reaction in a 14-Year-Old Boy after Accidental Overuse of Nasal Metoclopramide
}

\author{
Panagiota Zikidou ${ }^{a} \quad$ Rozeta Meziridou ${ }^{a}$ Sonia Alexiadou ${ }^{a}$ \\ Elpis Mantadakis ${ }^{a, b}$ \\ aDepartment of Pediatrics, University General Hospital of Alexandroupolis, \\ Alexandroupolis, Greece; 'bepartment of Pediatrics, Democritus University of Thrace, \\ Alexandroupolis, Greece
}

\section{Keywords}

Intranasal metoclopramide · Extrapyramidal side effects · Acute dystonic reaction

\section{Abstract}

We present the case of a 14-year-old boy who developed an acute dystonic reaction $5 \mathrm{~h}$ following the overuse of a nasal metoclopramide spray that his mother gave him thinking it was a nasal decongestant. The patient had torticollis and intense motor restlessness, while he was fully conscious and hemodynamically stable. All laboratory investigations were normal. He was treated with a single dose of biperiden intravenously with direct disappearance of the symptoms. Children are particularly susceptible to the extrapyramidal side effects of metoclopramide that can occur irrespective of the route of administration.

(C) 2021 The Author(s)

Published by S. Karger AG, Basel

\section{Introduction}

Acute dystonic reaction is an acute neurological condition, commonly seen in the emergency department that is characterized by involuntary muscle contractions that may manifest as torticollis, opisthotonus, dysarthria and/or oculogyric crisis [1]. Metoclopramide, one of the most commonly prescribed anti-emetics, may cause acute dystonic reactions at any age, 


\section{Case Reports in Acute Medicine}

Case Rep Acute Med 2021;4:1-6

\begin{tabular}{l|l|}
\hline DOI: 10.1159/000512655 & $\odot 2021$ The Author(s). Published by S. Karger AG, Basel \\
\hline
\end{tabular} www.karger.com/cra

Zikidou et al.: Acute Dystonic Reaction in a 14-Year-Old Boy after Accidental Overuse of Nasal Metoclopramide

most often in children and adolescents [2]. Clinical symptoms can develop within hours or even days after the administration of the drug, and can be misdiagnosed as tetanus, hypocalcemia, epileptic seizures and even meningoencephalitis [1]. We report the case of a 14-year-old boy who presented with acute dystonia caused by the accidental overuse of nasal metoclopramide. This is the first reported case of extrapyramidal adverse effects after intranasal administration of metoclopramide.

\section{Case Report}

A 14-year-old boy with no significant past medical history presented to the emergency department complaining of pain, neck stiffness and inability to move his head and control his body. On examination, he was conscious and anxious, with a blood pressure of 120/80 mm $\mathrm{Hg}$, pulse rate 89 beats/min, respiratory rate 20 breaths/min, oxygen saturation $99 \%$ on room air and temperature $36.3^{\circ} \mathrm{C}$. He had a twisted neck to the right (torticollis) (Fig. 1) and pronounced motor restlessness, consisting of continuous involuntary movements of the legs and arms. After asking the patient's mother, she admitted that her son was complaining of a stuffy nose about $5 \mathrm{~h}$ before visiting the hospital. So, she advised him to use a nasal spray that she had bought from the pharmacy. The patient used the nasal spray once with no relief. Hence, he repeated its use by taking approximately 25 puffs per nostril in order to relieve his symptoms. When the mother showed us the nasal spray, we realized that it was a metoclopramide nasal spray $(10 \mathrm{mg} /$ puff as metoclopramide hydrochloride) that she had bought believing it was a nasal decongestant. The recommended daily dose of this spray is 20-60 mg divided in two or three doses, as per the summary of product characteristics (SPC) of the drug [3]. The patient was admitted to the hospital for further management. All laboratory investigations including complete blood count, liver and kidney function tests, blood glucose, electrolytes and urinalysis were normal. Based on the sudden onset and rapid progression of the symptoms, the drug history and physical examination findings and since the patient was healthy prior to the described events, a diagnosis of metoclopramide-induced acute dystonic reaction was made. Therapeutically, a single dose of biperiden $0.04 \mathrm{mg} / \mathrm{kg}$ was administered intravenously. The dystonic symptoms disappeared quickly. The patient did not have any further dystonic reactions and was discharged home the following day.

\section{Discussion}

We describe the case of a 14-year-old boy who presented with an acute dystonic reaction induced by the inadvertent overuse of a metoclopramide nasal spray. Several case reports of dystonic reactions have been recorded worldwide in adults and children after oral or parenteral metoclopramide use. However, to the best of our knowledge, this is the first report of an acute dystonic reaction after the use of a nasal spray of metoclopramide [1, 2, 4-13].

Nausea and vomiting can be induced in several ways. The vomiting center receives signals from the gut, the vestibular labyrinths and the chemoreceptor trigger zone, which is in the area postrema of the medulla oblongata, where the dopamine, serotonin, histamine and muscarinic receptors are located. Symptoms of nausea and emesis are induced when these receptors are activated by their respective neurotransmitters, while specific antagonists are used for symptom relief [9].

\section{Karger'=}




\section{Case Reports in Acute Medicine}

Case Rep Acute Med 2021;4:1-6

\begin{tabular}{l|l}
\hline DOI: $10.1159 / 000512655$ & (c) 2021 The Author(s). Published by S. Karger AG, Basel
\end{tabular} www.karger.com/cra

Zikidou et al.: Acute Dystonic Reaction in a 14-Year-Old Boy after Accidental Overuse of Nasal Metoclopramide

Metoclopramide hydrochloride is a selective dopamine receptor antagonist used in the management of gastrointestinal and neurological disorders such as nausea, vomiting, gastroparesis, gastroesophageal reflux disease, dyspepsia, neurogenic bladder and migraine headaches due to its antagonistic activity against central and peripheral dopamine receptors $[9$, 12-14]. The antagonistic effect of metoclopramide on dopamine receptors in the basal ganglia disturbs the dopaminergic-cholinergic balance, and as a result, it decreases central dopamine transmission allowing an excess release of acetylcholine over dopamine [13]. As acetylcholine receptors are located on the musculature of the stomach, metoclopramide increases peristaltic movements and induces pyloric relaxation, resulting in a direct anti-emetic effect [9]. Thus, metoclopramide improves nausea and vomiting by two mechanisms, i.e., by accelerating gastric emptying through its peripheral action and by decreasing nausea and vomiting due to its central effect.

However, the antagonistic action of metoclopramide at the dopamine receptors in the basal ganglia is associated with extrapyramidal side effects, including acute dystonia, tardive dyskinesia, akathisia, and drug-induced parkinsonism [12]. The incidence of metoclopramideinduced extrapyramidal side effects is 1 in 500 patients and about $70 \%$ of them are females [10]. In children, the incidence of metoclopramide-induced acute dystonic reactions has been reported to be as high as 25\% [2]. Young adults, females, children, patients with a family history of neurological disorders, those receiving neuroleptics and patients that have family members who have had acute dystonic reactions due to metoclopramide are at particular high risk of developing metoclopramide-induced acute dystonic reactions $[2,7,9,12,13]$. Such reactions are more rarely seen in the elderly due to the loss of dopamine receptors [9]. Metoclopramide-induced acute dystonic reactions can also occur in patients carrying a CYP2D6 genetic polymorphism [9].

Acute dystonic reactions, the most common adverse extrapyramidal effects of metoclopramide are characterized by involuntary, slow and sustained or spasmodic contractions of muscle groups which may result in twisting, repetitive movements and abnormal posturing. They usually present as oculogyric crisis, torticollis or opisthotonus, rhythmic protrusion of the tongue, facial grimacing, trismus and bulbar speech [8, 11-13]. In our case, the patient presented with an acute dystonic reaction in the form of torticollis. In rare instances, the acute dystonic reaction may be life-threatening in case of laryngeal spasm that can lead to airway obstruction [12].

Acute dystonic reactions are a challenge for physicians in the emergency room since there is a high probability of misdiagnosis. When there is a dystonic reaction, the possibilities of tetanus, partial seizures, strychnine poisoning, hypocalcemia or other electrolyte abnormalities, labyrinthitis, encephalitis, meningitis, allergic reaction with swollen tongue or hyperventilation syndrome should be included in the differential diagnosis $[1,4,12,13]$. Eliciting a reliable drug history including use of over-the-counter medications is crucial to correct diagnosis, although the patient may be unable to speak or make the connection between symptoms and drug intake. Therefore, if the diagnosis is in doubt, one can reasonably treat as medication-induced acute dystonic reaction and then investigate further if no response to treatment is seen.

Metoclopramide is metabolized in the liver and it is usually administered per os, intramuscularly or intravenously. When taken per os, it acts within 15-20 min, whereas after parenteral administration, it acts within 1-3 min [1]. The nasal spray of metoclopramide was recently developed as an alternative delivery option to relieve symptoms associated with diabetic gastroparesis in adults [15-17]. The nasal spray of metoclopramide bypasses the gastric

\section{Karger'=}




\section{Case Reports in Acute Medicine}

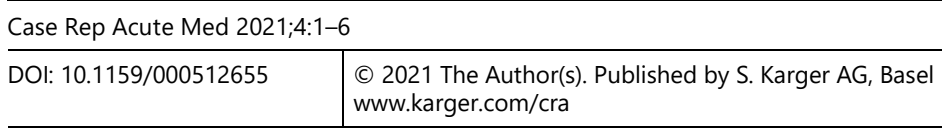
www.karger.com/cra

Zikidou et al.: Acute Dystonic Reaction in a 14-Year-Old Boy after Accidental Overuse of Nasal Metoclopramide

emptying, and few studies compare it favorably to oral administration of the drug with minimal side effects [15-17]. The clinical efficacy and tolerability of nasal metoclopramide spray has also been studied in patients with lung cancer, suggesting it is an effective, safe and cheap alternative for the prophylaxis and treatment of emetogenic chemotherapy [18]. According to the SPC of the spray our patient used, it is not recommended for use in infants because of the risk of extrapyramidal side effects.

When metoclopramide is taken, extrapyramidal symptoms usually start within a day and $94 \%$ of the symptoms occur within $72 \mathrm{~h}[7,9]$. The duration of symptoms may be proportional to the half-life of the drug, i.e., approximately $8 \mathrm{~h}[10,17]$. However, the "dystonic" dose of metoclopramide and risk factors for this reaction remain unclear, as there are reports of dystonic reactions even in recommended doses [11]. In fact, several recent studies suggest that metoclopramide-induced side effects are dose independent and unrelated to the drug concentrations in the blood $[1,2,4,6]$. Our patient developed symptoms approximately $5 \mathrm{~h}$ after the accidental overuse of the metoclopramide nasal spray.

The management of an acute dystonic reaction caused by metoclopramide involves immediate discontinuation of the drug, and rapid administration of intravenous or intramuscular anticholinergics or antihistamines, most often, benztropine, biperiden or diphenhydramine $[1,9,11,13]$. The intravenous route is preferred with signs and symptoms resolving within $10 \mathrm{~min}$, but the intramuscular route is an alternative in case of no intravenous access [13]. If no response is noted, administration of a second or third dose every 30 min may be required [1]. Benzodiazepines like diazepam induce immediate muscle relaxation and can be used in combination with anticholinergics [9]. Our patient was effectively treated with a single dose of intravenous biperiden.

\section{Conclusion}

The overdose of metoclopramide can cause extrapyramidal adverse effects even when administered intranasally, a usually safe route of administration. A careful history should be taken to detect drug use and misuse, including over-the-counter medications, and to provide diagnostic work-up, if necessary, in patients with dystonic reactions. Extrapyramidal symptoms have been reported to occur more frequently in young patients who take metoclopramide [19], but can also occur in elderly people. Finally, all physicians should be aware of the potential extrapyramidal side effects of metoclopramide that can occur irrespective of the route of administration [20].

\section{Statement of Ethics}

The patient's mother gave written informed consent to publish this case report including publication of the image.

\section{Conflict of Interest Statement}

The authors have no conflicts of interest to declare regarding the publication of this case report.

\section{Karger'=}




\section{Case Reports in Acute Medicine}

\begin{tabular}{l|l}
\hline DOI: 10.1159/000512655 & $\begin{array}{l}\text { (c) } 2021 \text { The Author(s). Published by S. Karger AG, Basel } \\
\text { www.karger.com/cra }\end{array}$ \\
\hline
\end{tabular}

Zikidou et al.: Acute Dystonic Reaction in a 14-Year-Old Boy after Accidental Overuse of Nasal Metoclopramide

\section{Author Contributions}

P.Z. conceived the work, searched the relevant literature and wrote the manuscript. R.M. clinically managed the patient in the ER and helped with literature search. S.A. helped with literature search and revised the manuscript. E.M. conceived the work, helped with the management of the patient in the ER, performed literature search, revised the manuscript prior to its submission, and takes full responsibility for its contents. All authors read and approved the final manuscript.

\section{References}

1 El Ç, Çelikkaya ME. Varied clinical presentations of acute dystonic reaction due to metoclopramide. Pediatr Emerg Care. 2019 May;35(5):369-72.

2 Koban Y, Ekinci M, Cagatay HH, Yazar Z. Oculogyric crisis in a patient taking metoclopramide. Clin Ophthalmol. 2014 Mar;8:567-9.

3 SPC. Veriligo®

4 Casteels-Van Daele M, Jaeken J, Van der Schueren P, Van den Bon P, Van den Bon P. Dystonic reactions in children caused by metoclopramide. Arch Dis Child. 1970 Feb;45(239):130-3.

5 Lavy S, Melamed E, Penchas S. Tardive dyskinesia associated with metoclopramide. BMJ. 1978 Jan;1(6105):77-8.

6 Bateman DN, Craft AW, Nicholson E, Pearson AD. Dystonic reactions and the pharmacokinetics of metoclopramide in children. Br J Clin Pharmacol. 1983 May;15(5):557-9.

7 Bateman DN, Rawlins MD, Simpson JM. Extrapyramidal reactions with metoclopramide. Br Med J (Clin Res Ed). 1985 Oct;291(6500):930-2.

8 Lou E, Abou-Zeid N. A case of metoclopramide-induced oculogyric crisis in a 16-year-old girl with cystic fibrosis. South Med J. 2006 Nov;99(11):1290-1.

9 van der Padt A, van Schaik RH, Sonneveld P. Acute dystonic reaction to metoclopramide in patients carrying homozygous cytochrome P450 2D6 genetic polymorphisms. Neth J Med. 2006 May;64(5):160-2.

10 Dingli K, Morgan R, Leen C. Acute dystonic reaction caused by metoclopramide, versus tetanus. BMJ. 2007 Apr;334(7599):899-900.

11 Arumugam J, Vijayalakshmi AM. Metoclopramide-induced oculogyric crisis presenting as encephalitis in a young girl. Indian J Pharmacol. 2012 Mar;44(2):266-7.

12 Oyewole A, Adelufosi A, Abayomi 0. Acute dystonic reaction as medical emergency: a report of two cases. Ann Med Health Sci Res. 2013 Jul;3(3):453-5.

13 Tianyi FL, Agbor VN, Njim T. Metoclopramide induced acute dystonic reaction: a case report. BMC Res Notes. 2017 Jan;10(1):32.

14 Hibbs AM, Lorch SA. Metoclopramide for the treatment of gastroesophageal reflux disease in infants: a systematic review. Pediatrics. 2006 Aug;118(2):746-52.

15 Parkman HP, Carlson MR, Gonyer D. Metoclopramide nasal spray is effective in symptoms of gastroparesis in diabetics compared to conventional oral tablet. Neurogastroenterol Motil. 2014 Apr;26(4):521-8.

16 Lankarani K. Is metoclopramide nasal spray an acceptable alternative to its oral form? Neurogastroenterol Motil. 2014 Jun;26(6):885.

17 Parkman HP, Carlson MR, Gonyer D. Metoclopramide Nasal Spray Reduces Symptoms of Gastroparesis in Women, but not Men, With Diabetes: Results of a Phase 2B Randomized Study. Clin Gastroenterol Hepatol. 2015 Jul;13(7):1256-1263.e1.

18 Tomirotti M, Dimaiuta M, Confalonieri M, Scanni A. Efficacy and tolerability of nasally administered compared to parenterally administered metoclopramide in the symptomatic treatment of chemotherapyinduced emesis in cancer outpatients. A controlled clinical study. Support Care Cancer. 1994 Nov;2(6):38992.

19 Yis U, Ozdemir D, Duman M, Unal N. Metoclopramide induced dystonia in children: two case reports. Eur J Emerg Med. 2005 Jun;12(3):117-9.

20 Tait P, Balzer R, Buchanan N. Metoclopramide side effects in children. Med J Aust. 1990 Apr;152(7):387. 
Case Reports in Acute Medicine
Case Rep Acute Med 2021:4:1-6 DOI: $10.1159 / 000512655$

(c) The Author(s). Published by S. Karger AG, Basel Zikidou et al:: Acute Dystonic Reaction in a 14-Year-Old Boy after Accidental Overuse of Nasal Metoclopramide

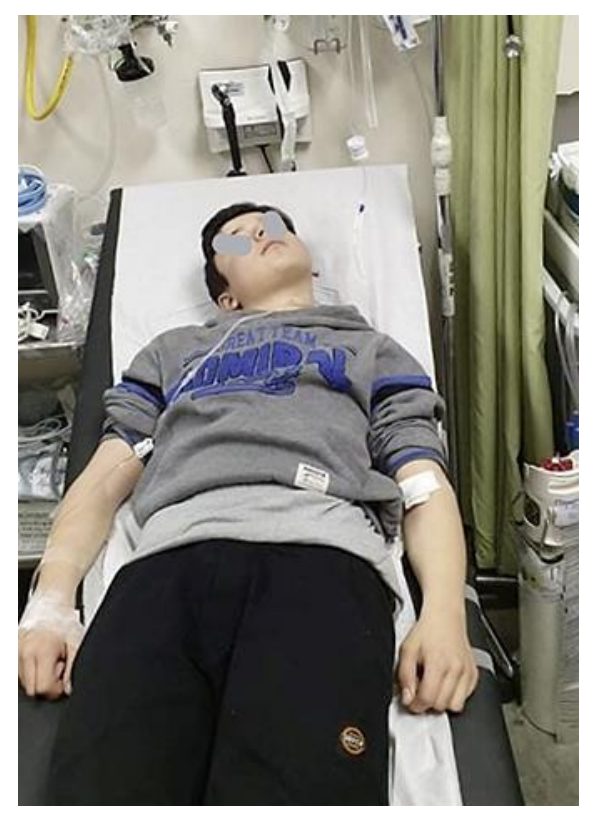

Fig. 1. Our patient in the emergency room. Note the prominent torticollis. 